\title{
Dynamic Capabilities, Business Strategy, Innovation and Performance of FMGC Campanies
}

\author{
Loo Chu Kiong \\ Department of Management, Universiti Teknologi Malaysia, Malaysia \\ chukiong@hotmail.com
}

\author{
Article Info \\ Journal of Journal of Enterprise and Business Intelligence (http://anapub.co.ke/journals/jebi/jebi.html) \\ Doi: https://doi.org/10.53759/5181/JEBI202101021 \\ Received 20 April 2021; Revised form 25 July 2021; Accepted 25 August 2021. \\ Available online 05 October 2021. \\ (C)2021 Published by AnaPub Publications.
}

\begin{abstract}
Majority of studies have been geared towards examining the critical role of business strategy, innovation and SMEs performance in Malaysia. Current studies, however, reported contradictory results on business strategy and innovation on financial performance in different contexts. Therefore, this study claims that there should be a moderating variable is required to promote the relationship between business strategy, innovation and organizational performance. This study, therefore, has incorporated the dynamic capabilities as a moderator to improve the relationship between business strategy (differentiation strategy and cost-leadership strategy), innovation (product innovation and process innovation) and financial performance. The study aims to describe the relationship of cost-leadership strategy, differentiation strategy, product innovation and process innovation on the financial performance under the moderating role of dynamic capabilities. To establish the proposed conceptual framework, two theories were introduced: resource-based view (RBV) and dynamic capabilities (DC). The recent literature was used to obtain information on the factors that enabled the present study to establish a conceptual framework and eight propositions formulated. The moderating effect of dynamic capabilities on business strategy (cost-leadership strategy and differentiation strategy) and innovation (product innovation and process innovation) are the main theoretical contribution. Furthermore, limitations and recommendations for future research presented.
\end{abstract}

Keywords- Business Strategy; Innovation; Dynamic Capabilities; Performance; SMEs.

\section{INTRODUCTION}

Small and medium enterprises (SMEs) are entities that are key to a country's economic growth. The importance of SMEs is represented by the emergence of over 90 per cent of all business establishments in every country, for instance, in Spain (99.8\%), Indonesia (99\%), Thailand (97.2\%) and Singapore (99\%) [1]. The scenario is relatively similar in Malaysia, where 98.5 per cent of all business establishments are the SMEs [2]. These establishments of SMEs prove that SMEs are the foundation of every country's economy. According to the SME Annual Report 2017, SMEs have played a significant role in fostering national revenue. However, the food manufacturing sector, statistics indicates that the contribution of food manufacturing SMEs to GDP in Malaysia is still low (34.4\%) as compared to neighbouring countries, for instance, Indonesia (60.3\%) and Thailand (41.1\%) [3]. These statistics showed that there is a problem that exists in the Malaysian food manufacturing industry. Consequently, the performance of food manufacturing SMEs in Malaysia needs serious attention.

However, the deep understanding of the relationship between cost-leadership strategy, differentiation strategy, product innovation, process innovation and financial performance of food manufacturing SMEs is still limited, even rare by considering dynamic capabilities as moderating variable. This study, therefore, identifies the relationship between cost-leadership strategy, differentiation strategy, product innovation, process innovation, organizational performance and moderating role of dynamic capabilities.

Cost-Leadership Strategy

\section{LITERATURE REVIEW}

In [2] has introduced a cost-leadership strategy term in the context of business strategy. The cost-leadership strategy is described as a business seeking to achieve the lowest manufacturing and distribution costs enabling it to cost less than its competitors Porter [4]. According to [3] defined a cost-leadership strategy as cost-reduction to achieve the cost advantage and internal market productivity. The recent definition refers to a cost-leadership strategy in the 
manufacturing industry through the usage of statistical quality control [5]. Porter proposes a cost-leadership strategy approach as a competitive advantage. By using a cost-leadership strategy, the defects, wastes, reducing operational and production costs can be avoided [6]. Firms also decrease the cost of human resources, raw material and distribution [7].

The fundamental principle is to reduce all costs involved. By using the cost-leadership strategy, a company can only achieve a competitive advantage on its rival by getting increased asset returns and delivering a quality product [7]. Thus, the disparity between product prices and costs will be reduced, and a firm will gain a competitive advantage by gaining massive returns.

Previous literature provides findings on cost-leadership strategy and performance, such as by [9] examined the relationship of cost-leadership with a performance at 119 small businesses in Kenya's furniture industry. The significant relationship also can be seen in a study by [8], the study examined 100 manufacturing SMEs in the relationship between strategic management practices and organizational performance in Kenya. The study found out those SMEs that employed cost-leadership strategy has a significant relationship on organizational performance. Besides, past studies of [10] investigate 278 manufacturing SMEs in Nigeria reported that cost-leadership strategy has a significant relationship with business performance. Besides, [11] found that a cost-leadership strategy positively influences export performance. This study explored with a sample of 247 of manufacturing SMEs in Portugal.

\section{DIFFERENTIATION STRATEGY}

Differentiation strategy seeks to be distinctive in its market with features valued by most consumers. According to Porter [12], differentiation strategy is the way to differentiate, for instance, brand, technology, customer care, sales and other measurements. Differentiation allows companies to create customer loyalty by providing innovative goods or services to better compete than rivals [13]. Hence, innovative companies will also focus on new steps to remain one step ahead of the competition.

Previous literature provides various findings on differentiation strategy and performance. Furthermore, in a study of 135 SMEs furniture manufacturing on the effect of generic strategy and firm performance, [4] report a significantly positive between differentiation strategy and firm performance. Another study on the competitive strategy found a positive relationship between differentiation strategy and firm performance [9]. Moreover, [14] found that differentiation strategy has a positive influence on firm performance. This study conducted among 100 manufacturing SMEs in Kenya. Recently, [15] investigated the competitive strategy and its effect on financial performance. The study found that firms that pursuing differentiation strategy has a positive influence on financial performance than without differentiation strategy.

\section{Product Innovation}

Product innovation is considered as the development of a new product by the use of new materials while changing the existing product to satisfy consumer [15], [16] described product innovation as a product shift, driven by a company research process and development. Product innovation is the creation and production of new types of products or services that complementing prior product deficiencies with more focus on quality. Product innovation is actively developing a new product package to meet consumer needs and added that product innovation offers a diversity of selection for products.

Previous literature provides findings on product innovation and performance. For instance, [17] found a positive link between product innovation and performance in Spanish manufacturing SMEs. [18] found positive product innovation and financial performance among SMEs in Indonesia's food manufacturing sector. [3] showed a positive association between product innovation has a significant relationship with performance of Greek manufacturing SMEs, [1] found that product innovation has a positive relationship with the firms' financial performance in the Iranian manufacturing SMEs. Additionally, a study by [5] also found that product innovation contributed positively to Indian manufacturing SMEs' financial results. In line with previous studies, [9] found a positive link between product innovation and business performance among SMEs in South-Eastern Europe.

\section{PROCESS INNOVATION}

In [12] clearly defined process innovation as "a new element introduced into an organization's production or service operations input materials, task specifications, work and information flow mechanisms, and equipment used to produce a product or render a service". The manufacturing process includes supporting materials, material input, semi-finished product, packaging materials, and finished product ready for distribution to customers. Process innovation seeks to save budgets rather than to acquire consumers or clients [13], [14]. Therefore, scholars suggest the positive effects of the implementation of process innovations [15], [9]. 
The link between process innovation and performance among manufacturing SMEs have well established by several researchers. For instance, [17], discovered that process innovation has a significant relationship with the productivity among 3,018 manufacturing SMEs in Ireland. Another empirical evidence by , [6] the result showed a Underpinning Theory And Conceptual Framework

In the field of strategic management, the concern is mostly on how firms achieve high performance. Several theoretical approaches for studying resources and financial performance, hence, this study will adopt the RBV theory and DC theory to explain the link of cost-leadership strategy, differentiation strategy, product innovation, process innovation, dynamic capabilities with financial performance. Organizations valuable, rare, imperfectly imitative and imperfect resources are the primary source of competitive advantage for best performance [17]. The idea of dynamic capabilities emerged as a dynamic version of RBV theory that matches rapidly changing environments. [4] described dynamic capabilities as a firm's capacity to build, integrate and reconfigure external and internal competencies to meet fast-growing environments. Hence, based on the DC theory, dynamic capabilities could be considered as a significant factor that could lead to superior performance.

The business strategy (cost-leadership strategy and differentiation strategy), innovation (product innovation and process innovation) and financial performance of manufacturing SMEs relationship may be improved by dynamic capabilities. Figure 1 below shows independent variables (cost-leadership strategy, differentiation strategy, product innovation, process innovation), dependent variable (financial performance) and moderator variable (dynamic capabilities). Based on the proposed conceptual framework, figure 1, eight propositions have developed.

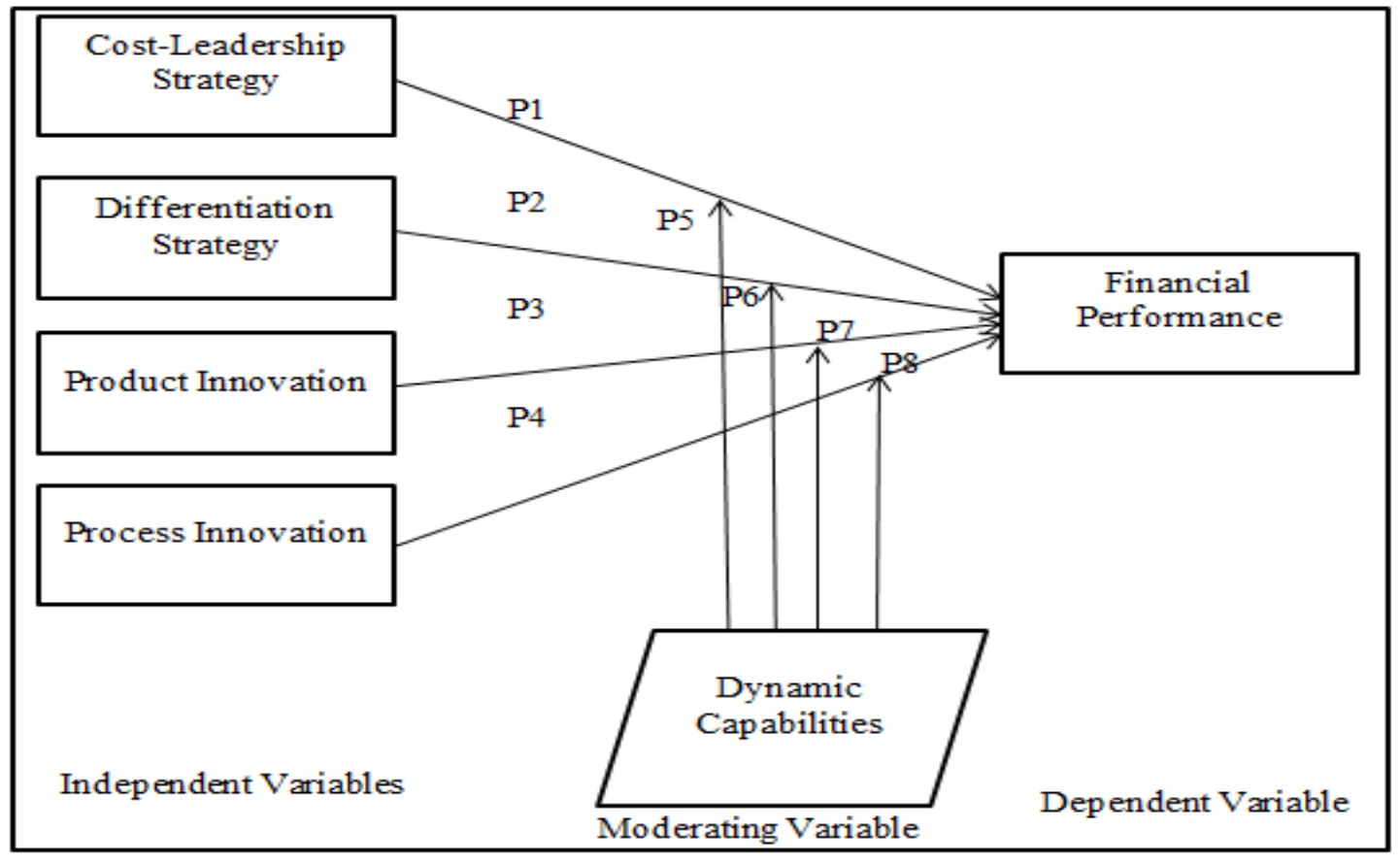

Propositions Development

Fig 1. Conceptual Framework

A cost-leadership approach seeks to achieve the lowest possible price, cost advantages, resources utilization and curve of experience [6]. According to [5], a cost-leadership strategy can lead to higher demand and higher market share. Previous empirical studies of cost-leadership strategy have shown the relationship with firm performance [9].

P1: Cost-leadership strategy is positively associated with financial performance.

The previous studies on differentiation strategy have a relationship with SMEs performance [3], [16], [3], Previous studies indicate the following proposition for the research.

P2: Differentiation strategy is positively associated with financial performance.

The finding of recent studies in manufacturing SMEs revealed the positive link of product innovation and manufacturing SMEs performance [2]. Hence, the research proposition is proposed for the study.

P3: Product innovation is positively associated with financial performance.

Recent studies among manufacturing SMEs found that process innovation has a relationship with performance [10]. Previous studies indicate the following proposition for the study. 
P4: Process innovation is positively associated with financial performance.

Numerous previous studies have indicated the importance of dynamic capabilities as well as its moderating effect in influencing the firm's performance. For instance, the recent studies among manufacturing SMEs have also found that dynamic capabilities significantly moderate the relationship the organizational performance [2], [8], [2], [4], [5], [3]. Therefore, the propositions below were formulated:

P5: Dynamic capabilities positively moderates the impact of cost-leadership strategy on financial performance.

P6: Dynamic capabilities positively moderates the impact of differentiation strategy on financial performance.

P7: Dynamic capabilities positively moderates the impact of product innovation on financial performance.

P8: Dynamic capabilities positively moderates the impact of process innovation on financial performance.

\section{DISCUSSION AND CONCLUSION}

Based on the conceptual framework, there is an indication of the relationship between cost-leadership strategy, differentiation strategy, product innovation, process innovation and financial performance where the dynamic capabilities can moderate the financial performance of SMEs. This review focuses primarily on the influence of moderating effect of dynamic capabilities. Consequently, dynamic capabilities represent the capacity of businesses to change and reconfigure existing resources and capability. This research's primary objective was to establish a conceptual framework by combining RBV and DC and eight hypotheses formulated. This research's prominent theoretical aspect is the integration of dynamic capabilities in the link between cost-leadership strategy, differentiation strategy, product innovation, process innovation and organizational efficiency in Malaysia's food manufacturing SME. No empirical evidence conducted and presented remains the limitation of this study. Empirical experiments using the proposed conceptual framework in different contexts to address this limitation may give a direction for future research.

\section{References}

[1]. C. A. Carrasco and E. D. Tovar-García, "Trade and growth in developing countries: the role of export composition, import composition and export diversification," Economic Change and Restructuring, vol. 54, no. 4, pp. 919-941, Aug. 2020.

[2]. G. A. Raju, "Impact of Export, Import, and GDP on Foreign Direct Investment of BRICS Countries - A Two Decade Tale," Journal of Advanced Research in Dynamical and Control Systems, vol. 12, no. SP4, pp. 1746-1752, Mar. 2020.

[3]. S. Bakari, "The Nexus between Export, Import, Domestic Investment and Economic Growth in Japan," International Academic Journal of Business Management, vol. 05, no. 02, pp. 1-9, Dec. 2018.

[4]. S. V. Kniaz, N. H. Heorhiadi, and I. O. Krasilych, "Technology Of Formation Of Enterprise Export-Import Activity Mechanisms," Scientific Bulletin Of Polissia, vol. 2, no. 3(11), pp. 34-42, 2017.

[5]. G. Lee and S.-B. Kim, "Technology Financing for Export-Import based Small and Medium Sized Enterprises: Focused on Supported Enterprises by the Export-Import Bank of Korea," Journal of Digital Convergence, vol. 14, no. 7, pp. 11-20, Jul. 2016.

[6]. K. S, V. R. D, and K. J, "A Study of Employees Motivation in Nagoorar Enterprises (Export \& Import) LTD-Chennai," Journal of Advanced Research in Dynamical and Control Systems, vol. 11, no. 0009-SPECIAL ISSUE, pp. 1253-1258, Sep. 2019.

[7]. R. M. Wilson, "Traffic congestion drives urban evolution," Physics Today, vol. 66, no. 12, pp. 18-18, Dec. 2013.

[8]. B. Li, D. Saad, and A. Y. Lokhov, "Reducing urban traffic congestion due to localized routing decisions," Physical Review Research, vol. 2, no. 3, Sep. 2020.

[9]. H. Zhang, "Integrating Urban Building Space and Transportation Space to Solve Traffic Congestion," World Construction, vol. 3, p. 7, Jun. 2014.

[10]. Q. Shen, X. Ban, and C. Guo, "Urban Traffic Congestion Evaluation Based on Kernel the Semi-Supervised Extreme Learning Machine," Symmetry, vol. 9, no. 5, p. 70, May 2017.

[11]. L. Karim, A. Daissaoui, and A. Boulmakoul, "Robust routing based on urban traffic congestion patterns," Procedia Computer Science, vol. 109, pp. 698-703, 2017.

[12]. H. Zhang, "Integrating Urban Building Space and Transportation Space to Solve Traffic Congestion," World Construction, vol. 3 , no. 1, p. 7, Jun. 2014

[13]. K. Bo, S. Ping, and K. Yun, "Research on the Algorithm of Automatic Urban Traffic Congestion Identification," Advanced Materials Research, vol. 926-930, pp. 3204-3207, May 2014.

[14]. Y. B. Dong, "Discussion on Urban Road Traffic Congestion Algorithm for Automatically Determining," Advanced Materials Research, vol. 926-930, pp. 3790-3793, May 2014.

[15]. J. L. Wang and H. B. Lai, "Congestion Analysis on Urban Traffic Network," Advanced Materials Research, vol. 756-759, pp. 1635-1638, Sep. 2013.

[16]. M. Wang and L. J. Xu, "Study on Traffic Congestion State Modeling of Urban Road," Advanced Materials Research, vol. 143-144, pp. 419-423, Oct. 2010.

[17]. Y. B. Sun and L. J. Liu, "The Countermeasures Response to Urban Traffic Congestion," Applied Mechanics and Materials, vol. 209-211, pp. 921-924, Oct. 2012.

[18]. C. Viauroux, "Pricing urban congestion: A structural random utility model with traffic anticipation," European Economic Review, vol. 55, no. 7, pp. 877-902, Oct. 2011. 